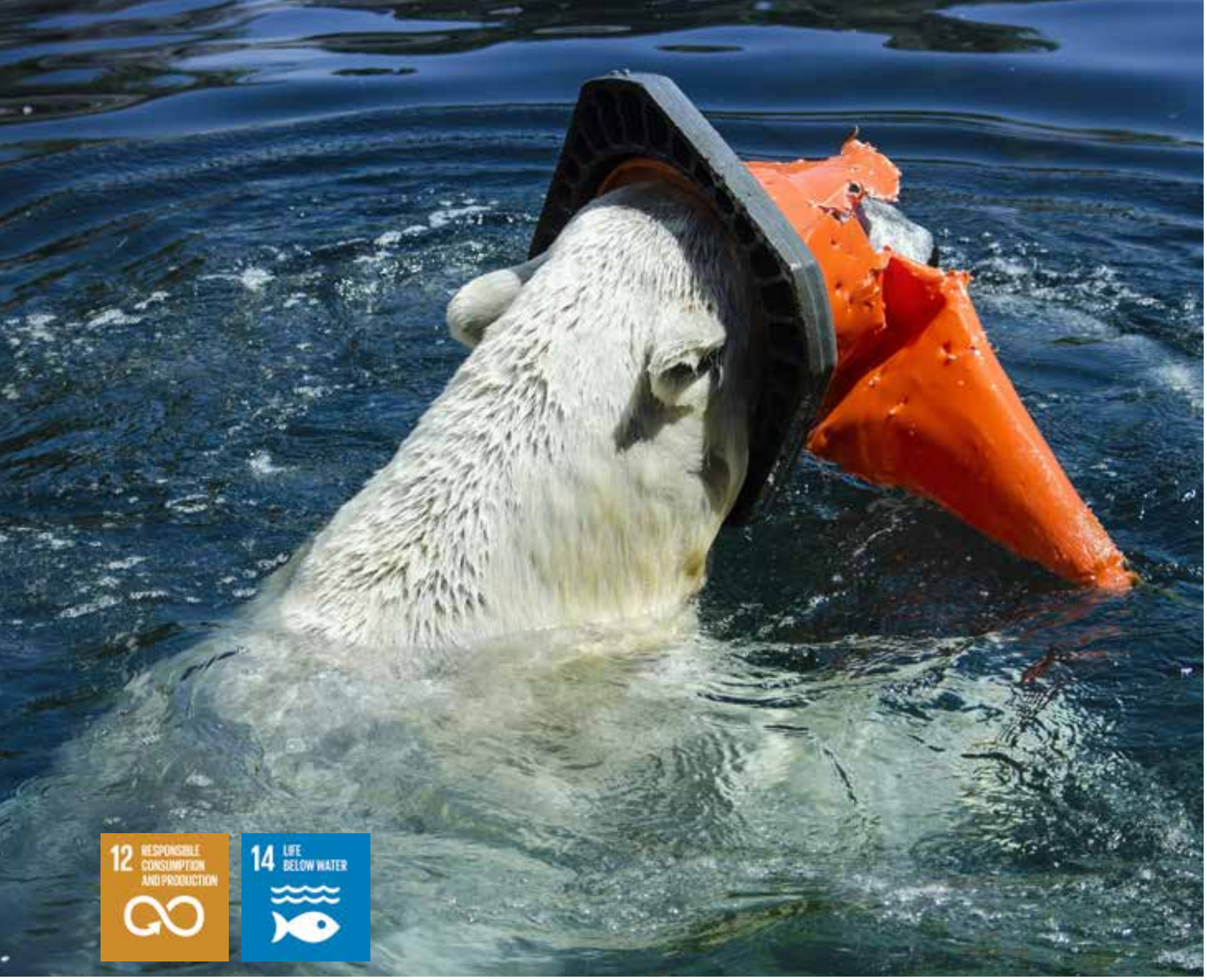

\title{
SDG 14: stepping up international efforts to tackle ocean plastic pollution
}

by Jivan Dasgupta

Eight to twelve million tons of plastics end up in the oceans every year. One of the targets of Sustainable Development Goal (SDG), Goal 14 on life below water, calls upon states to prevent and significantly reduce marine pollution of all kinds, in particular from land-based activities, including marine debris, by 2025. Following China's ban of all imports of non-industrial plastic wastes in 2018, exports of plastic wastes by high-income countries have shifted to South East Asian countries putting unbearable stress on their waste management systems. Despite worldwide attention devoted to the ocean plastics crisis, these practices are likely to aggravate the problem. It shows that current efforts are not sufficient to achieve the SDG target 14 for marine plastic litter and microplastics. 
China and South East Asia are considered the largest plastic polluters of the oceans. ${ }^{1}$ Strong economic growth in this region has not gone hand in hand with a parallel development of waste management systems. Nevertheless, high-income countries are exporting significant amounts of plastic waste intended for recycling to this region. Weaker environmental regulations and law enforcement in these countries make treatment of plastic wastes more competitive. Discrepancies in environmental standards are driving forces for transboundary movements for all sorts of waste from industrialized countries to emerging and developing economies. ${ }^{2}$

\section{G6}

SDG 14 on life below water calls upon states to prevent and significantly reduce marine pollution of all kinds, in particular from land-based activities, including marine debris, by 2025
Half of all plastic waste intended for recycling (14 million tons/annum) is exported by high-income countries. These waste streams are often mixed or contaminated, rendering them more difficult (or impossible) to recycle. Before the 2018 import ban, China was importing half of their plastic scrap (7 million tons). ${ }^{3}$ High-income countries integrate these exports in their "recycling" statistics without monitoring the fate of this plastic scrap in the importing country.

\section{Surge in illegal practices}

The China import ban has sent shock waves into the global plastic waste trade. High-income countries have underinvested in domestic recycling capacity for years. As a result, the bulk of these plastic wastes has been relocated to countries within China's vicinity such as Malaysia, Thailand and Vietnam. These countries lack the infrastructures to manage their own waste, let alone an abrupt increase of low quality waste streams which should be treated under strict environmental control at special treatment facilities. This has resulted in a surge of illegal recycling facilities, illegal dumping in the (marine) environment and open, unregulated burning of materials. ${ }^{4}$ Substantial environmental and health risks are associated with these practices.

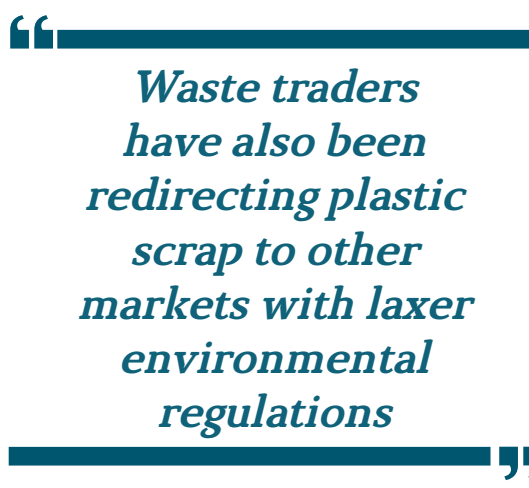

In recent months, these ASEAN countries have responded by imposing temporary import bans and restrictions. However, these restrictions are partially circumvented by illegal trafficking. These practices go from classifying waste as second hand goods or raw materials to mixing different types of waste and transporting waste on the black market. Waste traders have also been redirecting plastic scrap to other markets with laxer environmental regulations such as Indonesia and India. It shows

\footnotetext{
J. R. Jambeck et al., Marine pollution. Plastic waste inputs from land into the ocean, Science 347, 2015, p 768-771.

2 D. Kellenberg, Trading wastes, Journal of Environmental Economics and Management 64, 2012, p 68-87; J. R. Kitt, Waste Exports to the Developing World: a global response, The Georgetown International Environmental Law Review vol. 7, $1995, \mathrm{p} 485-514$.

3 A. L. Brooks et al., The Chinese import ban and its impact on global plastic waste trade, Science Advances Vol. 4, no. 6, 2018, DOI: 10.1126/sciadv.aat0131; C.A. Velis, Global recycling markets - plastic waste: A story for one player - China. Report prepared by FUELogy and formatted by D-waste on behalf of International Solid Waste Association - Globalisation and Waste Management Task Force. ISWA, Vienna, 2014.

4 Global Alliance for Incinerator Alternatives, Discarded - Communities on the Frontlines of the Global Plastic Crisis, 2019; Greenpeace Malaysia, The Recycling Myth - Malaysia and the Broken Global Recycling System, 2018; Shen Qu et al., Implications of China's foreign waste ban on the global circular economy? Resources, Conservation \& Recycling 144, 2019, p 252-255.
} 


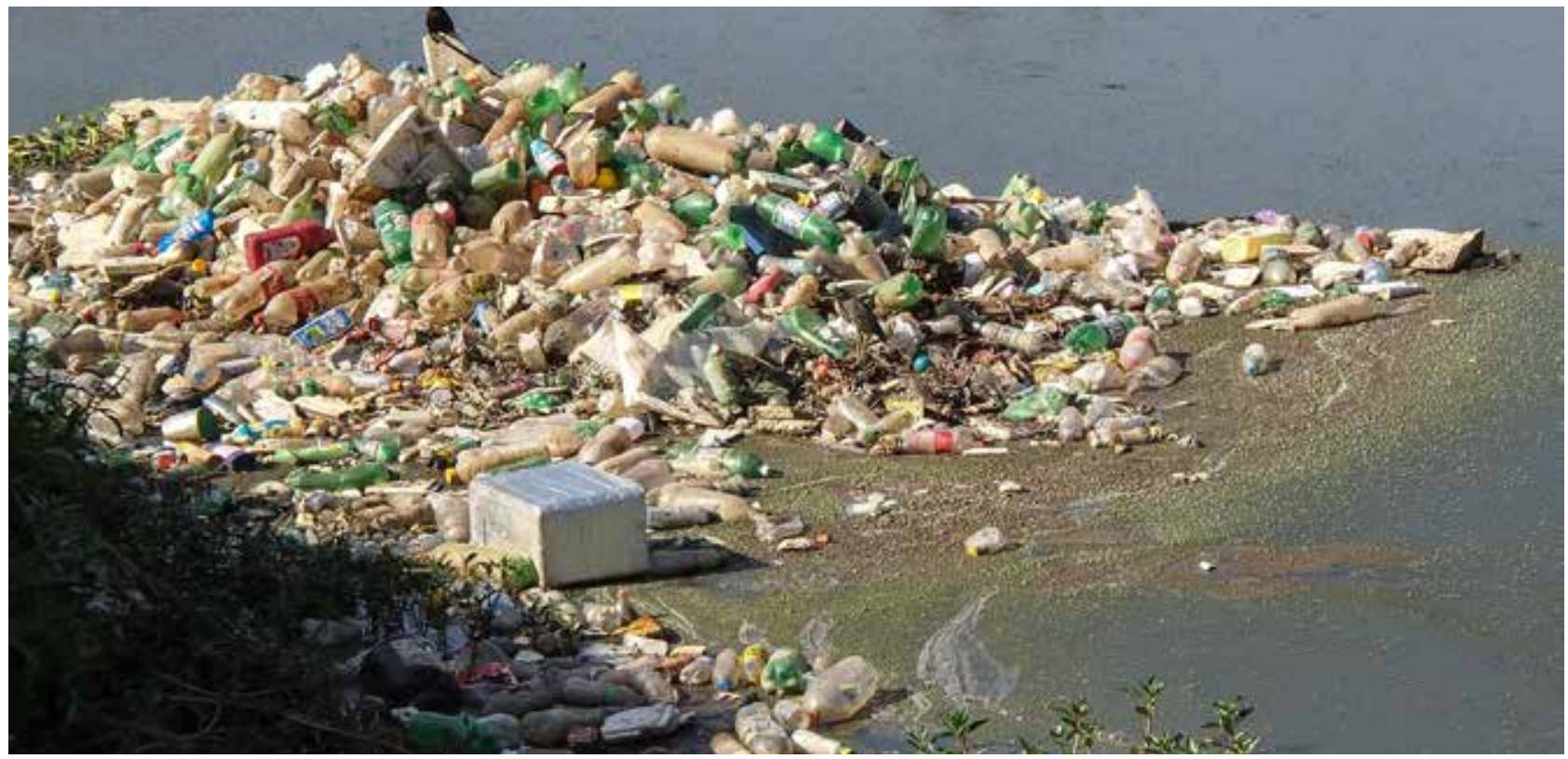

that waste follows the path of least resistance.

\section{Limitations of the Basel Convention and other treaties}

In May 2019, state parties decided to place plastic waste under the control mechanism of the Basel Convention on the Control of Transboundary Movements of Hazardous Wastes and Their Disposal. The underlying objective of the Convention is to improve the environmentally sound management of hazardous wastes and reduce their international trade through enhancement of trade controls. Once the amendment comes into force, an exporting country needs prior permission of the importing country to ship plas- tic wastes. In other words, the importing country is allowed to refuse the shipment, for example, if it does not have the capacity to manage it in an environmentally sound manner.

This amendment is a big step forward within the framework of the Basel Convention. However, policing and enforcement of the international waste trade (regulations) are inadequate in both exporting and importing countries. $^{5}$ Without rigorous enforcement capacities, illegal trafficking lurks right around the corner. Furthermore, the Basel Convention's contribution to enhancing the treatment and disposal of plastic wastes near the source of generation and limiting the export to countries with lower environmental standards has been limited.
There is a need to look at the broader picture. The overall weakness of the Basel Convention in addressing the ocean plastic pollution and the current chaos in global plastic waste trade lies in its core regulations, focused on the final (waste) phase in the lifecycle of plastics.

\section{4 \\ Without rigorous enforcement capacities, illegal trafficking lurks right around the corner}

"Upstream" processes in the lifecycle of plastics contribute largely to the current state of affairs. Strong population growth and unrestrained consumption

5 B. Appelqvist and J. Cooper, Waste Trafficking, Challenges And Actions To Be Taken, The International Solid Waste Association. 


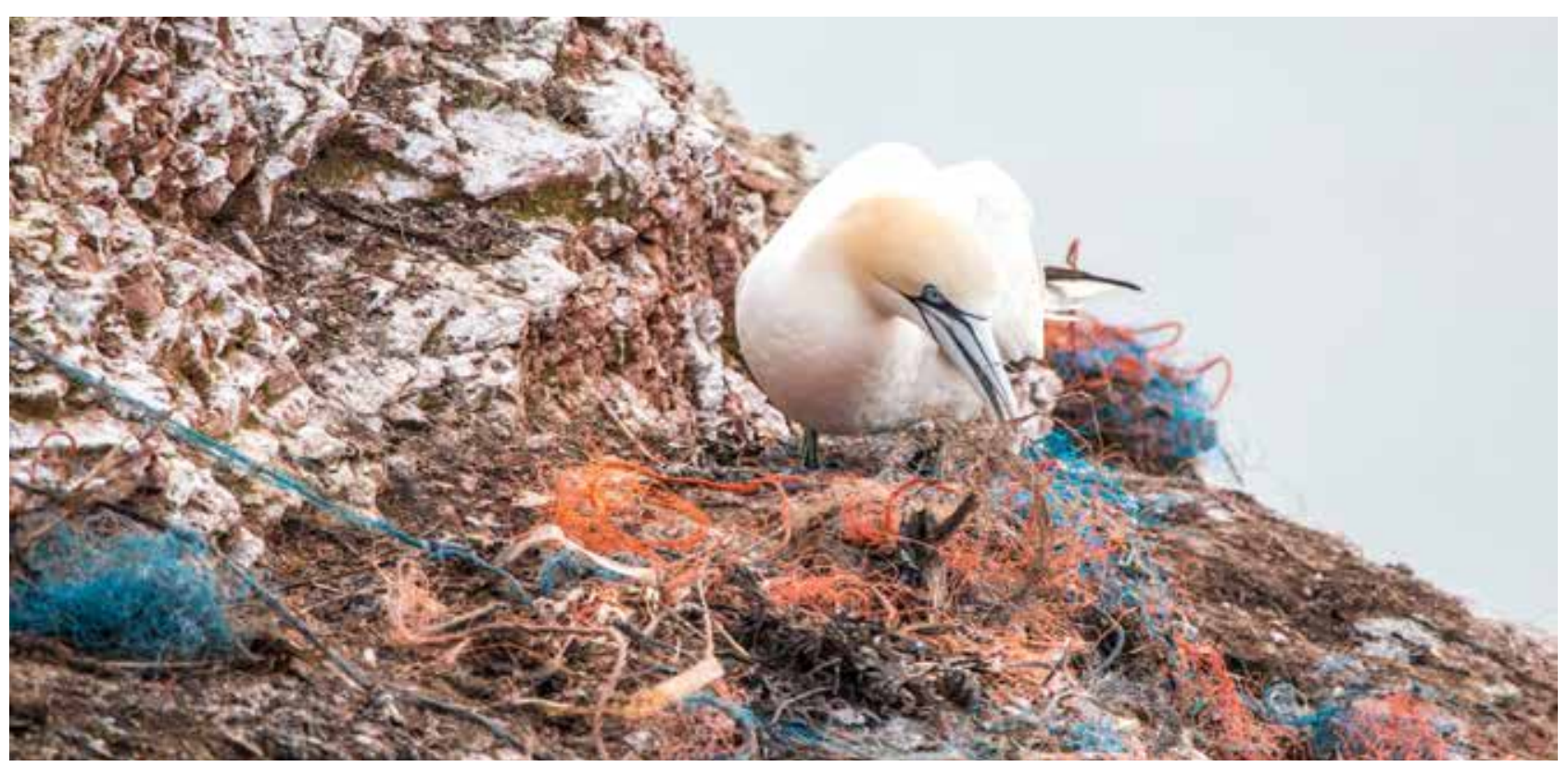

have caused the production of plastics to explode: from 1.5 million in 1950 to 348 million tons in $2018 .{ }^{6}$ In the $21^{\text {st }}$ century alone, more plastics were produced than in the whole $20^{\text {th }}$ century. In a business-as-usual scenario, global production is expected to quadruple by 2050 .

This exponential growth is exacerbated by poor recycling rates. The global recycling rate for all plastics ever produced is only $9 \%$ : $12 \%$ was sent for incineration and the remaining $79 \%$ was either landfilled or released into the (marine) environment. The problem is that the design of plastic materials does not take into account the after use needs of recycling. This is why high-income countries prefer to export their low value plastic wastes. Chemicals added to plastic products in order to enhance their functionality or aesthetic value hinder the recycling process. If plastic materials end up in the oceans, these toxic substances may leach into the marine environment, negatively affecting marine fauna.

There is no binding international convention with the primary objective to address landbased activities causing marine (plastic) pollution or the negative impacts of the globalized lifecycle of plastics. ${ }^{8}$ The Convention on the Law of the Sea (UNCLOS) is the only legally binding international treaty obligating states to take measures to prevent, reduce and control marine pollution from all sources on land and at sea. However, UNCLOS is a framework convention with general principles and does not prescribe specific measures nor environmental standards.

\section{A new international framework on prevention}

Besides the improvement of waste management, international efforts should focus primarily on the reduction and stricter regulation of primary plastics production as well as waste minimization. The way forward is to create a new legally binding international framework that encourages global actions across these pillars.

6 PlasticsEurope, Plastics - the Facts 2018 - An analysis of European plastics production, demand and waste data, 2019.

7 R. Geyer et al., Production, use, and fate of all plastics ever made, Science Advances 3, 2017, e1700782.

8 See also, UN Environment 2017, Combating marine plastic litter and microplastics: An assessment of the effectiveness of relevant international, regional and subregional governance strategies and approaches. 
The starting point for this framework would be to quantify the "significant reduction" target of SDG 14. Without quantification, this vague reduction target is merely adding up to the numerous general and vague provisions in the existing international legal framework.

States should have more ambition by setting binding global (or regional) reduction targets to achieve zero discharge of (plastic) litter and micro-plastics into the (marine) environment in the long term. Based on these targets for gradual reduction of marine plastics, states should establish national action plans consisting of national reduction targets and concrete measures.

The priority of these action plans should be to prevent (plastic) litter from entering the (marine) environment. ${ }^{9}$ The most direct way to do so is by committing to more waste prevention and improved waste management. In this regard, SDG 12 on sustainable consumption and production is of particular relevance. SDG 12 targets include achieving:

- sustainable management and efficient use of natural resources by 2030 (target 12.2);

- environmentally sound management of chemicals and all wastes throughout their life cycle, and significant reduction of their release to air, water and soil by 2020 (target 12.4);

- substantial reduction of waste generation through prevention, reduction, recycling and reuse by 2030 (target 12.5).

States should avoid unnecessary packaging and create a circular economy for plastics where design and format facilitates reuse and recycling and the waste management system is aligned with these recovery practices.

Considering that at least 2 billion people worldwide lack access to solid waste collection, in particular in developing countries, it goes without saying that the development of basic waste management facilities in these countries is a key component of prevention.

The Paris Climate Accord may serve as a model for a new international framework. Such an approach has the merit of creating a more level playing field between states and mobilizes international financing.

However, the flaws in the current international legal framework lie in the broad margin of discretion states have to regulate land-based sources of marine plastic pollution. This is enshrined in UNCLOS. The Convention provides that states shall "endeavor" to establish global rules on land-based sources of marine pollution, whilst for sea-based sources the wording "shall establish" is used. $^{10}$ States have been reluctant to give up national sovereignty on land-based sources as they are profoundly intertwined with national economic policy. International regulations on sea-based sources of marine pollution, on the other hand, are more advanced. The Marpol Treaty, which prohibits the discharge of plastic garbage by ships, and the London Protocol, which prohibits the dumping at sea of plastic waste from land, both illustrate this.

Therefore, a new international framework must demonstrate greater ambition by imposing specific additional measures at the international level.

The most straightforward "upstream" measure is to cap primary global plastics production from $100 \%$ fossil fuel sources. The political feasibility of such a measure is however unlikely.

A more acceptable solution may consist of banning or restricting (on a global scale) the production and use of the most harmful single use plastics, ${ }^{11}$ chemical additives and $\mathrm{mi}^{-}$

9 See also United Nations Environment Assembly, Resolution 3/7 “Marine litter and microplastics”, 4-6 December 2017.

10 Article 207, 4 and 211,1 UNCLOS.

11 See also, UN Environment, Legal Limits on Single-Use Plastics and Microplastics: A Global Review of National Laws and Regulations, 2018, https://www.unenvironment.org/news-and-stories/press-release/regulatory-landscape-single-use-plastics-shows-widespread-momentum 


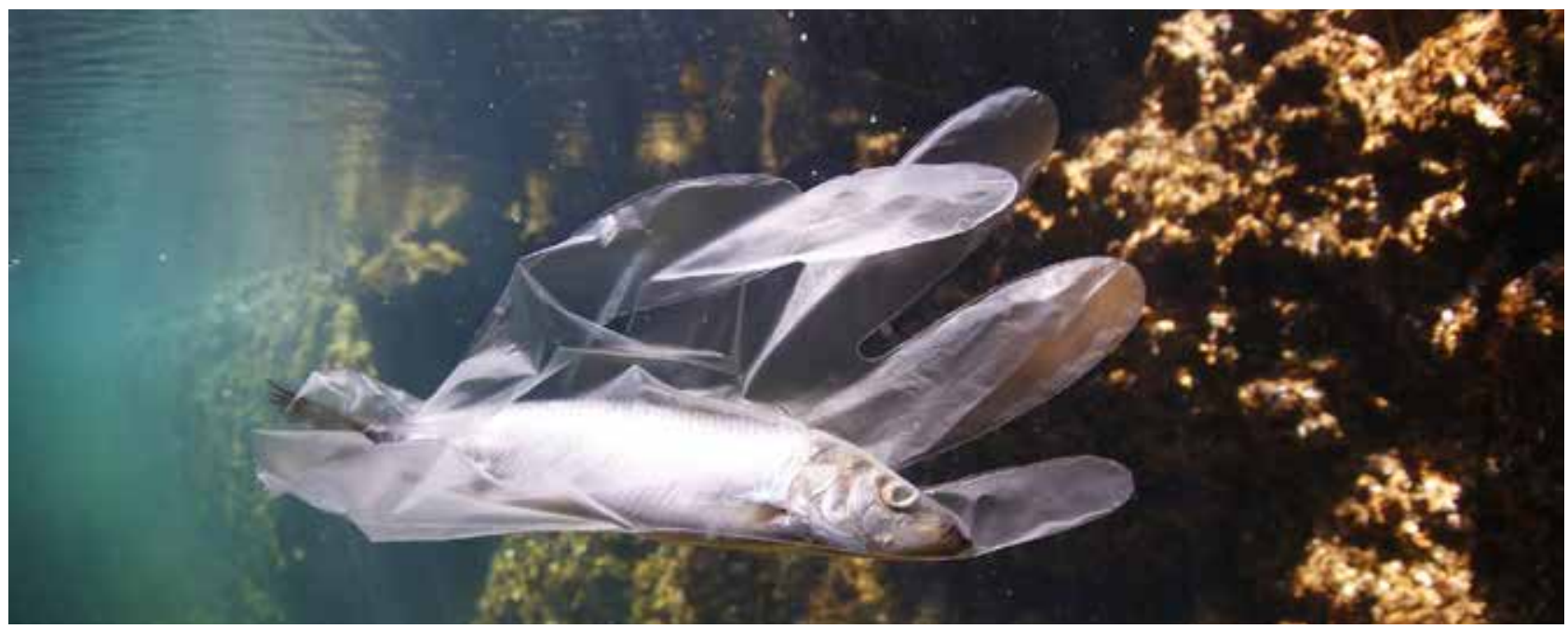

cro-plastics. This can certainly be done for plastic materials for which affordable and more environmentally sound alternatives exist or can be developed.

The mechanism of the Montreal Protocol, which successfully phased out substances depleting the ozone layer, may serve as a model for this option. Likewise, the European Union adopted in 2019 a directive to ban the single use plastics most found on $\mathrm{Eu}-$ ropean beaches, such as plastic cutlery, cotton buds and straws.

Furthermore, participating countries can be divided into two categories: countries with a high plastic waste generation per capita (developed countries) and countries with a high rate of mismanagement of plastic waste (emerging and developing countries). Dependent on the allocation to a certain category, states should set additional binding national reduction targets for the respective parameter.

A global fund may support the implementation of all these actions, in particular in the developing countries.

\section{Conclusion}

The current crisis in the global plastic waste trade results in illicit practices which further ex- acerbate environmental plastic pollution. It reveals the structural shortcomings in upstream and downstream processes in the globalized lifecycle of plastics. A new binding international agreement is recommended to address these shortcomings and eliminate discharge of plastics into the (marine) environment.

Worldwide attention to marine plastics has led to an unprecedented momentum to implement far-reaching measures. It is upon state leaders to grasp this opportunity and stop treating our oceans as a final dump for plastic wastes and to preserve the vital role the oceans play for our planet.

\section{The Author}

Jivan Dasgupta is a senior researcher at Ghent University (Belgium), Department of International, Public and European Law. His research primarily focuses on the development of a legal framework to tackle marine plastics and deep-sea mining in areas beyond national jurisdiction.

Prior to his academic activities, Jivan Dasgupta was a lawyer at the Brussels bar (Belgium) and served as advisor to a Belgian Deputy Prime Minister on energy and maritime transport policy. He also acted as in-house legal counsel for companies active in renewable energy, waste treatment and the development of maritime infrastructures and industrial zones. 